\title{
ANATOMIA DO CAULE DE Syagrus romanzoffiana (Cham.) Glassman
}

José Newton Cardoso Marchiori

Departamento de Ciências Florestais. Centro de Ciēncias Rurais. UFSM. Santa Maria, RS.

Graciela I. Bolzōn de Muñiz

Instituto de Tecnologia de la Madera. Universidad Nacional de San tiago del Estero, Argentina.

Aracely Vidal Gomes

Laboratōrio de Anatomia da Madeira. Setor de Ciências Agrārias. Uni versidade Federal do Paraná. Curitiba, PR.

RESUMO

A estrutura anatômica do caule de Syagrus romanzoffiana (Cham.) Glassman ë descrita e ilustrada com fotomicrografias. Os ca racteres observados são analisados, com base na escassa literatura existente sobre o estipe de palmeiras.

SUMMARY

MARCHIORI, J.N.C.; MUNIZ, G.I.B. de and GOMES, A.V., 1988. Anatomy of the stem of Syagrus romanzoffiana (Cham.) Glassman. Ciência e Natura, 10:99-103.

The anatomical structure of the stem of syagrus romanzof fiana (Cham.) Glassman is described and illustrated whith photomi crographs. The structure is analysed, based on the scarce anatomical literature concerning to the stem of palm trees.

INTRODUÇAO

0 coqueiro riograndense, ou gerivā, tem sido frequentemen te referido na literatura botānica como pertencente ao gênero Are castrum, de Beccari. Estudos mais atualizados, entretanto, como a recente revisão de GLASMAN (3), não mais consideram os gêneros Are castrum, Arikuryroba, Barbosa e Glaziova como vālidos, reunindo-os em Syagrus Martius.

0 gēnero Arecastrum era monotỉpico, incluindo apenas a espécie estudada no presente trabalho. ALVES \& DEMATTE (1) relacio naram 44 espécies de syagrus para a flora brasileira, sendo, depois de Bactris, o género com maior número de representantes no paỉs.

0 gerivā é nativo em vārios habitats no leste, centro e sul do Brasil, alcançando o Paraguai, Uruguai e Argentina (REITZ, 5). E espécie de extraordināria beleza, sendo muito cultivada como ornamental nas regiões tropicais e subtropicais do mundo. As folhas novas fornecem agradāvel palmito comestỉvel e as adultas ótima ração para animais domésticos. Os frutos são comestīveis e o estipe é la r gamente usado em estivados, pinguelas e nos trapiches de ägua salga da, por não ser atacado por xilōfagos marinhos (REITZ, 5 ).

As referências anatômicas são extremamente escassas sobre 
esta palmeira. TOMLINSON (6) descreveu a estrutura da folha e raíz, com base em material proveniente do Jardim Botānico de Singapura. A estrutura do caule é desconhecida, sendo descrita pela primeira vez no presente trabalho.

De acordo com os caracteres anatômicos do xilema, a famî lia Palmae é relativamente evoluỉda dentre as monocotiledôneas, apre sentando vasos em raizes, caules e folhas. Com relação aos elementos vasculares, são encontradas placas desde exclusivamente escalarifor mes (Chamaedorea, Nypa), até exclusivamente simples, como no gênero Phoenix (CARLQUIST, 2 ).

\section{MATERIAL E METODOS}

0 material analisado è procedente de Faxinal dos Guedes, Santa Catarina, e encontra-se registrado no Herbārio do Departamen to de Ciências Florestais, da Universidade Federal de Santa Maria, com o no 3185 .

Da amostra de caule foram preparados bloquinhos, orienta dos para a obtenção de cortes transversais e longitudinais. Logo após a coleta e preparo dos bloquinhos, procedeu-se à fixação dos mesmos em álcool 70\%. Os bloquinhos foram posteriormente amolecidos por fervura em àgua, submetidos à inclusão com polietilenoglicol 1000, e cortados em micrótomos de deslizamento, regulado para espessura nominal de $20 \mu \mathrm{m}$. Os cortes foram coloridos com acridina-vermalha, crisoidina e azúl-de-astra, e montados em lāminas permanentes com Entellan.

Foram também preparadas lâminas de macerado. Usou-se o método de Jeffrey (FREUND, 4) e coloração com safranina.

As fotomicrografias foram tomadas em aparelho Carl Zeiss, no Laboratōrio de Anatomia da Madeira, da Universidade Federal do Paranā.

DESCRIÇAO DO CAULE

Região externa totalmente esclerosada, com cerca de 1000 $\mu \mathrm{m}$ de espessura, formada basicamente por peridermes, células corti cais e pequenos feixes vasculares (Figura la).

Córtex relativamente estreito, com 3000 a $4000 \mu \mathrm{m}$ de es pessura, composto de células parenquimáticas tangencialmente alonga das, pequenos feixes de fibras esclerenquimáticas e feixes de maior diâmetro, providos de tecidos vasculares colaterais. A disposição das células de parênquima cortical, denuncia a ocorrência de divi sões anticlinais nas mesmas. Nos feixes vasculares, o floema situase externamente ao xilema (Figura la).

Cilindro central com uma zona periférica apresentando abun dantes feixes vasculares, rodeados por maciço envoltōrio de fibras esclerenquimáticas. Cada feixe possui 1, geralmente 2 a 4 poros de 

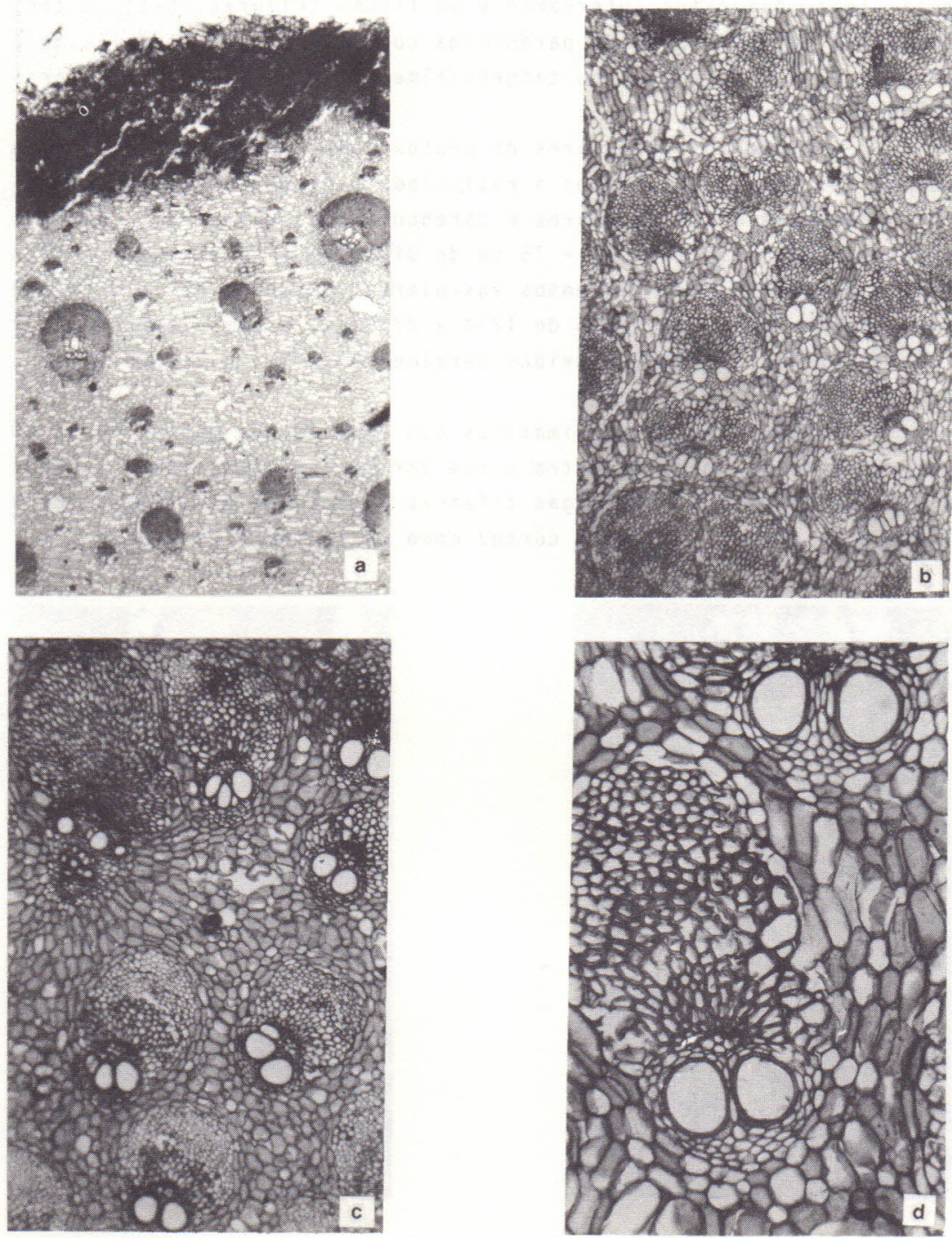

Figura 1 - Fotomicrografias do caule de Syagrus romanzoffiana

a) Região externa do caule, mostrando tecidos esclerosados na superfície e córtex composto de células parenquimáti cas em arranjo tangencial, pequenos feixes de fibras $\bar{e}$ feixes vasculares colaterais $(22 x)$.

b) Corte transuersal do cilindro central (22 x).

c) Aspecto do cilindro central $(35 x)$, destacando feixes vas culares e disposição das células parenquimáticas do tecī do matriz.

d) Feixes vasculares do cilindro central, providos de 2 va sos de metaxilema $(88 x)$. 
metaxilema, dispostos internamente ao floema (Figuras 1b-d). 0 tec $\underline{i}$ do matriz diferencia-se do parēnquima cortical por ter cēlulas mais longas em direção radial ou tangencialmente aos feixes vasculares (Figura $1 c, d$ ).

Elementos vasculares de protoxilema, providos de espessa mentos anelados, espiralados e reticulados. Elementos de metaxilema, com pontuações intervasculares e parēnquimo-vasculares em arranjo escalariforme; com $15-33-75 \mu \mathrm{m}$ de diâmetro e de paredes finas $(2,5-3,9-6,4 \mu \mathrm{m})$. Elementos vasculares com cerca de $1823 \mu \mathrm{m}$ de comprimento mēdio, variando de 1214 a $2700 \mu \mathrm{m}$, e com placas de per furação escalariformes, providas geralmente de 1 a 6 barras (Figura 2a).

Fibras esclerenquimāticas com comprimento médio de 1520 $\mu \mathrm{m}$; cerca de $11 \mu \mathrm{m}$ de diāmetro e com paredes pouco espessas. Corpos silicosos, presentes em longas fileiras adjacentes aos feixes vascu lares e de fibras, tanto no cōrtez como no cilindro central.
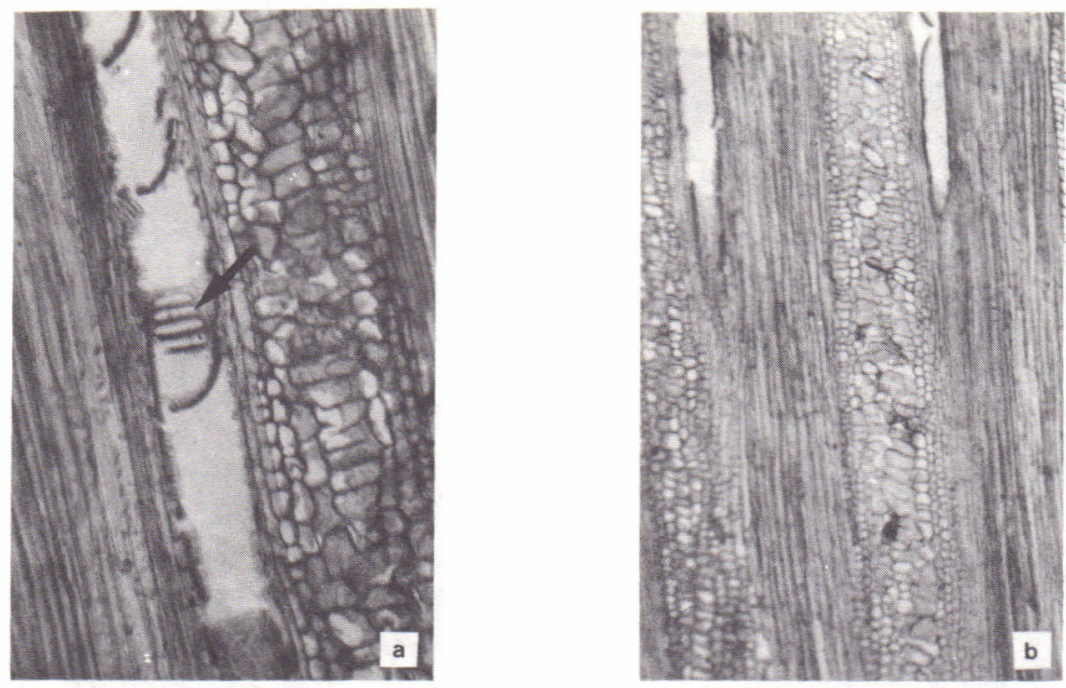

Figura 2 - Detalhes anatómicos do caule de Syagrus romanzoffiana

a) Vaso com placa de perfuração escalariforme, em corte 1on gitudinal $(88 \mathrm{X})$.

b) Feixes vasculares em corte longitudinal (35 X).

ANALLISE DA ESTRUTURA ANATŌMICA

0 caule de Syagrus romanzoffiana apresenta alguns aspectos peculiares em relação à outras espécies de palmeiras do sul do Bra sil. O conhecimento anatōmico desta familia $\bar{e}$, entretanto, muito in consistente, tornando-se necessārias investigações mais amplas para 
se poder estimar o real valor taxonómico dos diferentes caracteres. os feixes vasculares em palmeiras são do tipo colateral, com o floema situado externamente ao xilema. Os feixes na espécie em estudo caracterizam-se pela presença de vārios poros no metaxile ma e bainhas esclerenquimāticas muito desenvolvidas no lado abaxial. A presença de placas escalariformes confere ao gēnero um caráter primitivo dentro da famīlia, de acordo com a interpretação de CARL QUIST (2).

A ausência de feixes fibrosos no cilindro central, a dis posição das células componentes do tecido matriz e do parênquima cor tical, permitem uma fácil separação do material em estudo dos gêne ros Bactris e Geonoma.

LITERATURA CITADA

1. ALVES, M.R.P. \& DEMATTE, M.E.S.P. Palmeiras - caracteristicas bo tânicas e evolução. Campinas, Fundação Cargi11, 1987. 129 p.

2. CARLQUIST, S. Ecological strategies of xylem evolution. Berkeley, University of California Press, 1975. 259 p.

3. GLASSMAN, S.F. A revision of the B. E. Dahlgren's Index of Ameri can Palms. Lehre, Verlag von J. Cramer. 1972.

4. FREUND, H. Handbuch der Mikroskopie in der Technik. Frankfurt, Umshan Verlag, 1970 v.5, pt2, 379 p.

5. REITZ, R. Palmeiras. Itajaí, Flora Ilustrada Catarinense, 1974. $189 \mathrm{p}$.

6. TOMLINSON, P.B. Anatomy of the Monocotyledons. II. Palmae.oxford, Clarendon Press, 1961. $453 \mathrm{p}$.

Recebido em outubro, 1988; aceito em novembro, 1988. 
